\title{
Modified Fracture Mechanics Approach for Hydraulic Fracturing Stress Measurements
}

\author{
Guiyun Gao $\mathbb{D}^{1,2}$ Chenghu Wang $\mathbb{D}^{2},{ }^{2}$ Hao Zhou $\mathbb{D}^{2}, 2$ and Pu Wang $\mathbb{D}^{2}$ \\ ${ }^{1}$ Key Laboratory of Shale Gas Exploration, Ministry of Natural Resources, Chongqing Institute of Geology and Mineral Resources, \\ Chongqing 401120, China \\ ${ }^{2}$ National Institute of Natural Hazards, MEMC (Former Institute of Crustal Dynamics, China Earthquake Administration), \\ Beijing 100085, China
}

Correspondence should be addressed to Guiyun Gao; gygaopku@163.com and Chenghu Wang; huchengwang@163.com

Received 13 June 2020; Revised 23 September 2020; Accepted 15 October 2020; Published 4 December 2020

Academic Editor: Zongqing Zhou

Copyright (c) 2020 Guiyun Gao et al. This is an open access article distributed under the Creative Commons Attribution License, which permits unrestricted use, distribution, and reproduction in any medium, provided the original work is properly cited.

\begin{abstract}
Hydraulic fracturing (HF) test has been widely used to determine in situ stress. The use of a conventional continuum method for this purpose has raised considerable controversies concerning field tests, particularly in the determination of the maximum horizontal principal stress under preexisting fractures. Fracture mechanics methods are very promising when considering preexisting cracks. However, most fracture mechanics methods do not include the effects of confinement on fracture parameters that depend on confining stress. In the present paper, we proposed a modified approach based on fracture mechanics for stress determination considering the relation between fracture toughness and confining stress based on the Rummel and Abou-Sayed methods. Then, we conducted true triaxial hydraulic fracturing tests under different stress ratios for granite and sandstone specimens to verify the proposed approach. The observed typical pressure-time curves indicate that in the conducted hydraulic fracturing tests, the steady fracture growth was attained. Moreover, we demonstrated that the stress ratios influence crack orientations. The horizontal maximum principal stresses determined using the modified Rummel method achieve the lowest relative error compared with other considered stress estimation approaches. This modified fracture mechanics method could be used as a potential alternative approach to obtain a considerably more precise estimation of the maximum horizontal stress in hydraulic fracturing stress determination.
\end{abstract}

\section{Introduction}

In situ stress measurement can be performed to address a wide range of geomechanical problems, including faulting, earthquakes, and shale gas exploitation, as well as geothermal and geotechnical problems [1-9]. A hydraulic fracturing (HF) test (also referred to as a minifrac or microfrac test), in which a particular small volume of fluid is injected to create a hydraulic fracture, has been widely applied to in situ stress determination. The largest advantage of such test over other stress measurement approaches lies in its capability of estimating both stress magnitudes and orientations $[10,11]$. In particular, a reliable estimate of minimum horizontal principal stress $S_{\text {hmin }}$ can be obtained by instantaneous shut-in pressure at which vertically induced hydraulic fractures in a vertical borehole arrest and start to close $[12,13]$.
However, concerning maximum horizontal principal stress $S_{\text {Hmax }}$, it can be evaluated indirectly based on elastic theory and Kirsch's solution which is only valid for a homogenous defect-free continuum [12]. It requires an accurate determination of either fracture reopening pressure or the rock tensile strength suitable for in situ HF tests. The applicability of this continuum method to $S_{\mathrm{Hmax}}$ estimation has been discussed in many studies $[14,15]$. The assumptions of Kirsch's solution are not reasonable when hydraulic fractures or preexisting natural fractures exist [16]. Both borehole image logging and core analysis have revealed that the natural or mechanically induced fractures near a borehole may exist $[6,17]$. When the length of fractures exceeds a certain value, the influence of a fracture cannot be neglected [18]. The natural fractures, induced fractures, or other discontinuities such as bedding planes influence stress determination in 
terms of preexisting fracture surface opening or even fracture initiation and propagation [19]. The generalized HF method, called hydraulic tests on preexisting fractures (HTPF) method, was introduced by Cornet and Valette [20] based on the exact stress balance between the fluid pressure and normal stress across the preexisting fracture. However, the HTPF method is time-consuming and requires a minimum of 14-15 tests to determine the stress state [12]. Diagnostic fracture injection test (DFIT), which was originally coined by Halliburton and has been widely used by industries [21], is a comprehensive small-volume fracture injection test. DFIT can be used to estimate the properties of rock formations including the leak-off coefficient, permeability, fracture closure pressure, and formation pressure [22]. However, DFIT estimates only the minimum principal stress and mainly focuses on leak-off behavior or preexisting fracture extension when considering preexisting natural fractures [21]. Here, we intend to determine maximum principal stress which cannot be accurately estimated by conventional methods for stress determination from hydraulic injection tests. Moreover, fracture initiation is the main concern for stress measurement that needs to be analyzed using the fracture mechanics method.

Linear elastic fracture mechanics has been used for stress evaluation in HF tests and has been proven to be appropriate in many cases [23-26]. For in situ stress measurements, fracture toughness is an important parameter in this type of fracture mechanics approaches that can be determined through fracture tests using a cracked chevron-notched Brazilian disc or a semicircular bend specimen as suggested by ISRM [27, 28]. However, fracture toughness depends on the stress state and can be affected by confining stress that has barely been considered and incorporated in the analysis of stress determination using fracture mechanics approaches [29-31]. Fracture toughness obtained based on the in situ hydraulic fracture measurement can be one to two orders of magnitude larger than that acquired as a result of a laboratory core experiment. Laboratory rock fracture testing results have indicated that fracture toughness can increase by $10 \%-$ $350 \%$ with increasing confining pressure [32-34]. Therefore, this effect needs to be considered when the principles of fracture mechanics are used for HF analysis for a more precise assessment of in situ stress.

In the present study, we modify the existing fracture mechanics approaches for HF tests to incorporate the confining stress effect on fracture toughness. Then, we conduct the true triaxial HF tests under different stress ratios using the granite and red sandstone samples. The stresses applied to these cubic specimens are estimated using the proposed fracture mechanics method and conventional continuum approaches to verify the validity of the modified fracture mechanics method.

\section{Fracture Mechanics Approach for HF Stress Measurements}

2.1. Conventional and Fracture Mechanics Approaches for $H F$ Stress Measurements. The conventional theory underlying HF stress measurements is based on Kirsch's solution in an elastic medium obtained considering stress around a circular hole $[35,36]$. The principal stresses in a vertical borehole corresponding to the critical state under fluid pressure can be expressed as follows [35]:

$$
S_{\mathrm{H} \max }=T_{0}+3 P_{\mathrm{s}}-P_{\mathrm{b}}-P_{0} \text {, }
$$

or

$$
\begin{gathered}
S_{\mathrm{H} \max }=3 S_{\mathrm{hmin}}-P_{\mathrm{r}}-P_{0}, \\
S_{\mathrm{hmin}}=P_{\mathrm{s}},
\end{gathered}
$$

where $S_{\mathrm{Hmax}}$ and $S_{\mathrm{hmin}}$ are the maximum and minimum horizontal principal stress, respectively; $T_{0}$ is the tensile strength of surrounding rock; $P_{0}$ is the pore pressure; $P_{\mathrm{b}}$ is the breakdown pressure; $P_{\mathrm{s}}$ is the instantaneous shut-in pressure. Vertical stress can be calculated based on the overburden weights of rock at respective depths. Compared with equation (1), equation (2) is more commonly used in practice in the cases that do not require considering tensile strength measurements in cored rocks despite the difficulty in the interpretation of $P_{\mathrm{r}}$ [14].

However, the conventional theory underlying HF ignores the possibility of preexisting fractures, as well as their initiation during $\mathrm{HF}$, which may result in misleading in the HF process and the unreliability of equations (1) and (2) in $S_{\text {Hmax }}$ calculation [23]. For example, it was discovered that natural fractures in core samples from the tests on the Devonian Shale corresponding to the Rome Basin of West Virginia violated the assumptions used in the conventional methods in the calculation of in situ stress [23]. The fracture mechanics approach for HF stress determination was therefore deemed neccesary.

There were several attempts to interpret HF based on fracture mechanics, including the numerical and theoretical approaches $[23,25,26,37,38]$, but very few of them attempted to estimate in situ stresses based on fracture mechanics [23, 25]. Abou-Sayed et al. [23] proposed an approach based on the fracture mechanics concepts to evaluate the in situ stress by conducting field and laboratory tests. To realize such a method, they assumed two symmetrical fractures emanating radially from a borehole in an infinite medium. In the case of the original crack perpendicular to $S_{\text {hmin }}$, the maximum horizontal principal stress $S_{\text {Hmax }}$ can be defined as follows [23]:

$$
S_{\mathrm{H} \max }=\frac{K_{\mathrm{Ic}}}{(G-F)(\pi a)^{1 / 2}}-\frac{F}{(G-F)} P_{\mathrm{b}}+\frac{G}{(G-F)} P_{\mathrm{s}},
$$

where $K_{\mathrm{Ic}}$ is the fracture toughness, $a$ is the half crack length, $G$ and $F$ are the functions of $a / R$ [39], and $R$ is the radius of a borehole.

The other fracture mechanics approach to perform the HF stress measurement was introduced by Rummel [25] grounded on the basic principle of the superposition of stress intensity factors corresponding to each loading source acting 
on the symmetrical double cracks with half-length $a$ :

$$
K_{\mathrm{I}}\left(S_{\text {Hmax }}, S_{\mathrm{hmin}}, p, p_{\mathrm{a}}\right)=K_{\mathrm{I}}\left(S_{\mathrm{H} \max }\right)+K_{\mathrm{I}}\left(S_{\mathrm{hmin}}\right)+K_{\mathrm{I}}(p)+K_{\mathrm{I}}\left(p_{\mathrm{a}}\right),
$$

where $K_{\mathrm{I}}$ indicates the stress intensity factor for the crack propagation of mode I fracture, $p$ is the fluid pressure acting on the wall of a hole, and $p_{\mathrm{a}}=p_{\mathrm{a}}(x, 0)$ characterizes the fluid pressure distribution along the crack from $x=(R,-R)$ to $x$ $=(R+a,-R-a)$. According to the general formulation of the stress intensity factor for a tension crack with halflength $a$ in an infinite plate, as given by Paris and Sih [39], and considering Kirsch's equation, we can derive the first two terms at the right of equation (5) as follows:

$$
\begin{aligned}
& K_{\mathrm{I}}\left(S_{\mathrm{H} \max }\right)=-S_{\mathrm{H} \max } \sqrt{R} f(b), \\
& K_{\mathrm{I}}\left(S_{\mathrm{hmin}}\right)=-S_{\mathrm{hmin}} \sqrt{R} g(b),
\end{aligned}
$$

where $f(b)=-2\left(\left(b^{2}-1\right) /\left(\pi b^{7}\right)\right)^{1 / 2}, g(b)=(\pi b)^{1 / 2}(1-(2 / \pi)$ $a \arcsin (1 / b))+2\left(b^{2}+1\right)\left(\left(b^{2}-1\right) /\left(\pi b^{7}\right)\right)^{1 / 2}$, and $b=1+a /$ $R$. Assuming that no fluid penetrates into existing cracks, the third term in equation (5) can be expressed as follows:

$$
K_{\mathrm{I}}(p)=p \sqrt{R} h_{0}(b)
$$

where $h_{0}(b)=1.3\left((b-1) /\left(1+b^{3 / 2}\right)\right)+7.8((\sin [(b-1) / 2]) /($ $\left.\left.2 b^{5 / 2}-1.7\right)\right)$. Then, the pressure acting within a crack yields stress intensity that can be defined as follows:

$$
K_{\mathrm{I}}\left(p_{\mathrm{a}}\right)=p \sqrt{R} h_{\mathrm{a}}(b)
$$

If $p_{\mathrm{a}}(x)=p$, for example, we obtain $h_{a}=(\pi b)^{1 / 2}(1-(2 /$ $\pi) a \arcsin (1 / b))$.

Thereafter, the maximum horizontal principal stress introduced in equation (5) underlies the following relation at an unstable crack extension:

$$
S_{\mathrm{H} \max }=\frac{\left[-\left(K_{\mathrm{Ic}} / \sqrt{R}\right)-S_{\mathrm{hmin}} g+\left(h_{0}+h_{\mathrm{a}}\right) P_{\mathrm{b}}\right]}{f} .
$$

In the fracture mechanics approaches proposed by AbouSayed et al. [23] and Rummel [25], a key parameter is fracture toughness $K_{\mathrm{Ic}}$. However, the fracture toughness obtained based on the in situ hydraulic fracture measurement is larger than that acquired as a result of conducting a laboratory core experiment [40] and has a strong dependency on confining stress $[30,32,41]$. Therefore, if we apply equation (4) or (9) to analyze the maximum horizontal principal stress, we may incorrectly estimate the in situ stress or that derived in a laboratory tests.

2.2. Confining Effects and Modified Approach for HF Stress Measurements Based on Fracture Mechanics. Laboratory rock fracture tests revealed that fracture toughness increased with confining stress $[32,34]$. Most researchers have indicated the presence of the positive relation between confining stress and fracture toughness. Based on experimental results, Winter [42] suggested formulating this relation as follows:

$$
K_{\mathrm{Ic}}^{\prime}=\left(1+0.038 P_{\text {conf }}\right) \times K_{\mathrm{Ic}}^{0}
$$

where $K_{\mathrm{Ic}}^{\prime}$ is the fracture toughness under confining pressure $\left(\mathrm{MPa} \mathrm{m}{ }^{1 / 2}\right), K_{\mathrm{Ic}}^{0}$ is the fracture toughness at ambient pressure $\left(\mathrm{MPa} \mathrm{m}^{1 / 2}\right)$, and $P_{\text {conf }}$ is confining pressure $(\mathrm{MPa})$. This relation conforms to the results of Schmidt and Huddle [34] and Abou-Sayed [23], as demonstrated by Stoeckhert et al. [43]. Müller [41] proposed a similar relation by incorporating the pore pressure based on the three-point bending test under confining pressure. Vásárhelyi [31] assumed that the connection between the fracture toughness of gneiss and the hydrostatic pressure was linear and proposed a linear dependency similarly as in equation (10) by fitting the experimental data, which varied according to the direction of anisotropy. Funatsu et al. [29], however, formulated the relation between fracture toughness and confining pressure using the $R$ curve method based on the square of confining pressure.

However, the above equations have a critical drawback, i.e., the dimension problem, due to the simple mathematical fitting of the experimental data. Here, a semiempirical method can be utilized to analyze the relation between fracture toughness and confining pressure, combined with the experimental data reported in the related research works $[29,30,32,42-46]$. The tensile strength of rock material needs to be considered when we explore the correlation between fracture toughness and confining pressure to retain dimension consistency. As a result of analyzing the fracture toughness variation depending on different values of confining pressure, we proposed a uniform form equation as follows:

$$
K_{\mathrm{Ic}}^{\prime}=\left(1+C \frac{P_{\mathrm{conf}}}{T_{0}}\right) \times K_{\mathrm{Ic}}^{0}
$$

where $T_{0}$ is tensile strength and $C$ is the dimensionless coefficient that corresponds to the dependence of fracture toughness on confining stress together with $T_{0}$ and $K_{\mathrm{Ic}}^{0}$. The relation between fracture toughness and confining pressure was concisely represented by fitting the experimental data and using the above equation [47]. The fitting results also revealed that coefficient $C$ could be approximated to $\sim 0.5$, while the range of tensile strength for various rocks here was $0.6 \sim 25 \mathrm{MPa}$, as presented in our previous work [47]. Accordingly, equation (11) can be reduced as follows:

$$
K_{\mathrm{Ic}}^{\prime}=\left(1+0.5 \frac{P_{\text {conf }}}{T_{0}}\right) \times K_{\mathrm{Ic}}^{0} .
$$

Once we obtain the fracture toughness under the confining stress state, we can use this modified fracture toughness equation to realize an approach of the fracture mechanics for HF stress measurement. The modified Abou-Sayed and Rummel methods for $S_{\mathrm{Hmax}}$ are defined similarly as in equations (4) and (9) except substituting $K_{\mathrm{Ic}}$ in these equations by 
$K_{\text {Ic }}^{\prime}$ as follows:

$$
\begin{gathered}
S_{\text {Hmax }}=\frac{K_{\mathrm{Ic}}^{\prime}}{(G-F)(\pi a)^{1 / 2}}-\frac{F}{(G-F)} P_{\mathrm{b}}+\frac{G}{(G-F)} P_{\mathrm{s}}, \\
S_{\text {Hmax }}=\frac{\left[-\left(K_{\mathrm{Ic}}^{\prime} \sqrt{R}\right)-S_{\mathrm{hmin}} g+\left(h_{0}+h_{\mathrm{a}}\right) P_{\mathrm{c}}\right]}{f} .
\end{gathered}
$$

\section{True Triaxial HF Tests}

3.1. Test Apparatus and Specimen Processing. The true triaxial testing apparatus designed by the former Institute of Crustal Dynamics, China Earthquake Administration, was used to address true triaxial confinement. This apparatus comprises three main parts: loading frames, servo-hydraulic system, and control system as well as transducers and software (Figure 1). The loading frames have stiffness higher than $1 \mathrm{GN} / \mathrm{m}$ and can accommodate specimens with a dimension of $700 \times 500 \times 500 \mathrm{~mm}^{3}$. The servo-hydraulic system and the loading frames are designed to produce output forces up to 1000 and $400 \mathrm{kN}$ in the vertical and two horizontal directions, respectively, which can yield a vertical stress up to $100 \mathrm{MPa}$ and horizontal stresses up to $40 \mathrm{MPa}$ on a 100 $\times 100 \mathrm{~m}^{2}$ cross-sectional area. The servo control system controls the independent loading and maintenance of three principal stresses. A hand pump with a maximum pulse output of $60 \mathrm{MPa}$ was used for hydraulic loading so that the loading rate was monitored to maintain consistency as much as possible. Hydraulic pressure was monitored and recorded using a high-precision sensor and subacquisition system.

Two kinds of rock specimens, granite and red sandstone, were selected for hydraulic fracturing tests. The granite samples were collected in Lushan city, Jiangxi province, China, while the red sandstone samples were obtained in Yunnan province. The rock samples we used were from quarries near the surface beneath the weathering layer. The lithology of the granite samples is two-mica granite of the Xingzi formation (HtX). Moreover, the lithology of sandstone samples is red sandstone of the Shuanglongtan formation ( $\epsilon 2 \mathrm{~s})$, the Middle Cambrian system. The physical and mechanical properties of these rock samples are summarized in Table 1. Fracture toughness was evaluated through the ISRM-suggested semicircular bend test [28].

The granite and red sandstone specimens were processed into $100 \mathrm{~mm} \times 100 \mathrm{~mm} \times 100 \mathrm{~mm}$ cubes. A through hole with a diameter of $10 \mathrm{~mm}$ was drilled in each granite specimen. Concerning the red sandstone specimen, the diameter of the through borehole was $15 \mathrm{~mm}$ with a pair of symmetrical cracks in the direction of one principal stress (Figure 2). The length of these prefabricated cracks was approximately $2.5 \mathrm{~mm}$. The open-hole HF experiments were conducted by injecting fluid directly into the boreholes of cubic specimens (Figure 1(b)).

3.2. Experiment Design. Based on the horizontal stress ratio range in mainland China [48], the experiment program was designed, as shown in Table 2. The direction of wellbores was along the direction of $F_{3}$ to simulate vertical stress in a vertical borehole, while horizontal stresses were perpendicular to a borehole (Figure 1(b)). Concerning the specimens with prefabricated cracks, the maximum horizontal principal stress was parallel to their direction. The horizontal stress ratios $k_{\mathrm{H} \max }=S_{\mathrm{H} \max } / S_{\mathrm{v}}$ and $k_{\mathrm{hmin}}=S_{\mathrm{h} \min } / S_{\mathrm{v}}$ were in the range of 1.5 3.0 and 0.5 1.5, respectively. The ratio between the minimum and maximum horizontal stresses was from 0.5 to 0.75 , representing the typical value of tectonic stress in China.

3.3. Experiment Procedure. In the conducted experiments, preloads were almost simultaneously applied in three directions at a low loading rate $(0.015 \mathrm{MPa} / \mathrm{s}$, corresponding to $\sim 30 \%$ of the following normal loading rate of $0.05 \mathrm{MPa} / \mathrm{s}$ ) to a value of $5 \mathrm{kN}$ (Figure 3). In the loading stage (under stress boundary conditions), stress $\sigma_{3}$, corresponding to $F_{3}$, was first applied in the horizontal direction, parallel to the borehole, and then, the maximum and minimum horizontal stresses were simultaneously applied in $F_{1}$ and $F_{2}$ directions, respectively, perpendicular to the borehole. Finally, the hydraulic stress was applied to pressurize the test interval at the constant flow rate using a hand pump to simulate the HF process for stress measurements. As soon as fracture breakdown (or reopening) pressure was reached and pressure stabilized, we stopped the pump and recorded the closure of fractures. Then, we depressurized the hole and waited before executing the next injection cycle. Finally, at least five injection cycles were implemented. Cyclic hydraulic pressure with respect to time was recorded for stress determination.

\section{Results and Discussion}

4.1. HF Test Results of Granites. To confirm the validity of the proposed HF testing system under triaxial loading, we first conducted two HF tests using granite samples. Figure 4 represents the hydraulic pressure changes with the time of the considered granite specimens in true triaxial and hydraulic loading. Breakdown pressure $P_{\mathrm{b}}$ of two granite specimens HF-JG-2 and HF-JG-5 is $14.42 \mathrm{MPa}$ and $18.73 \mathrm{MPa}$, respectively. The fracture reopening pressure $P_{\mathrm{r}}$ and instantaneous shut-in pressure $P_{\mathrm{s}}$ are also clearly observed in each pressure cycle and determined using the interactive software developed base Visual Basic [49]. The calculated HF parameters and stresses based on equations (2) and (3), respectively, are summarized in Table 3 .

The maximum and minimum horizontal principal stresses applied on specimen HF-JG-2 are 9.83 and $4.86 \mathrm{MPa}$, respectively, while the corresponding calculated stresses from the HF tests are 7.08 and $5.16 \mathrm{MPa}$, respectively (Table 3). The relative error associated with the determined maximum and minimum horizontal principal stresses is $27.98 \%$ and $6.24 \%$, respectively. The calculated maximum and minimum horizontal principal stress estimates for specimen HF-JG-5 are 14.12 and 7.63 MPa, respectively, and the corresponding errors with respect to the applied maximum and minimum horizontal principal stress are $2.82 \%$ and $4.11 \%$, respectively. The tensile strength values calculated 


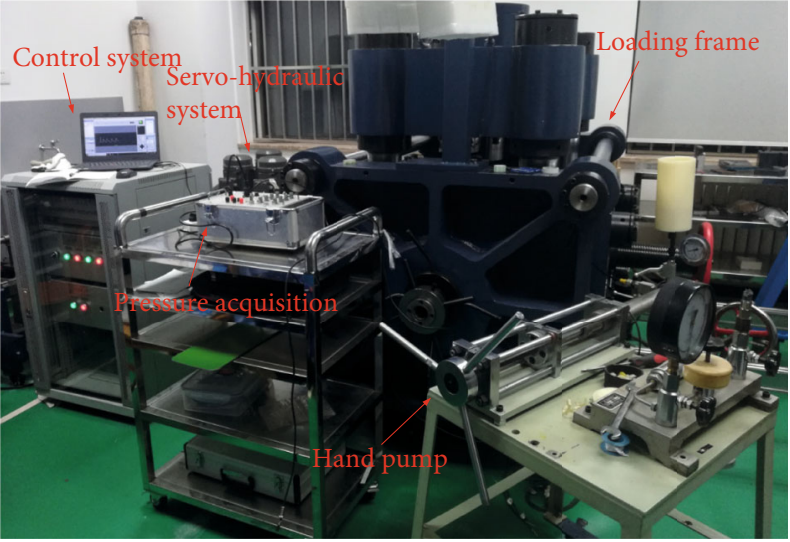

(a)

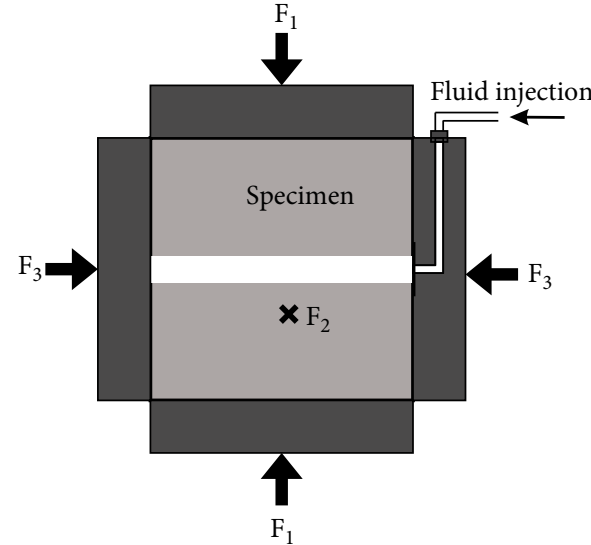

(b)

Figure 1: (a) True triaxial HF testing system and (b) schematic drawing of a specimen under triaxial loadings and hydraulic pressure.

TABle 1: Physical and mechanical properties of the rock samples.

\begin{tabular}{lccccc}
\hline Lithology & $\begin{array}{c}\text { Density } \\
\left(\mathrm{g} / \mathrm{cm}^{3}\right)\end{array}$ & $\begin{array}{c}\text { Elastic modulus } \\
(\mathrm{GPa})\end{array}$ & Poisson's ratio & $\begin{array}{c}\text { Tensile strength } \\
(\mathrm{MPa})\end{array}$ & $\begin{array}{c}\text { Fracture toughness } \\
\left.(\mathrm{MPa} \mathrm{m})^{1 / 2}\right)\end{array}$ \\
\hline Granite & 2.65 & 50.0 & 0.18 & 10.87 & 1.07 \\
Red sandstone & 2.50 & 28.8 & 0.18 & 5.3 & 0.78 \\
\hline
\end{tabular}

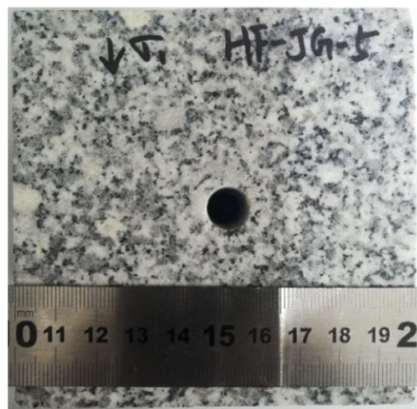

(a)

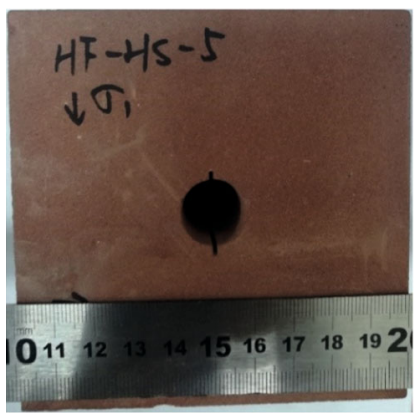

(b)

FIgUre 2: Typical specimens used in true triaxial HF tests. (a) Granite specimen with a through hole. (b) Through-hole red sandstone specimen with the diametrically opposed cracks.

TABle 2: Experiment design.

\begin{tabular}{lcccccc}
\hline Sample no. & $\begin{array}{c}S_{\mathrm{Hmax}} \\
(\mathrm{MPa})\end{array}$ & $\begin{array}{c}S_{\mathrm{hmin}} \\
(\mathrm{MPa})\end{array}$ & $\begin{array}{c}S_{\mathrm{v}} \\
(\mathrm{MPa})\end{array}$ & $k_{\mathrm{H} \max }$ & $k_{\mathrm{hmin}}$ & $S_{\mathrm{hmin}} / S_{\mathrm{H} \max }$ \\
\hline HF-JG-2 & 9.83 & 4.86 & 6.81 & 1.44 & 0.71 & 0.49 \\
HF-JG-5 & 14.53 & 7.33 & 4.86 & 2.99 & 1.51 & 0.50 \\
HF-HS-1 & 9.76 & 6.11 & 4.93 & 1.98 & 1.24 & 0.63 \\
HF-HS-2 & 9.95 & 6.22 & 6.20 & 1.61 & 1.00 & 0.63 \\
HF-HS-3 & 9.90 & 7.47 & 4.99 & 1.98 & 1.50 & 0.75 \\
HF-HS-4 & 9.84 & 4.94 & 6.16 & 1.99 & 0.80 & 0.50 \\
HF-HS-5 & 9.91 & 5.98 & 4.98 & 1.66 & 1.20 & 0.60 \\
\hline
\end{tabular}

based on the HF data are 6.02 $\mathrm{MPa}$ and 9.96 $\mathrm{MPa}$, which are smaller than the tensile test results (namely, $\sim 10.87 \mathrm{MPa}$ ).

For granite samples, we located and identified the induced fractures using the ink dyeing method. Figure 5 represents the fracture morphology after applying hydraulic fracturing to specimens HF-JG-2 and HF-JG-5. The length values of the cracks induced by the HF of these specimens were approximately $20 \mathrm{~mm}$. However, the crack direction of HF-JG-2 was close to the maximum horizontal principal stress, while the orientation of the other specimen HF-JG-5 deviated by $45^{\circ}$ from the maximum horizontal principal stress.

Considering the simulated critical injection pressure versus the fracture length as shown by Stoeckhert [46], the critical injection pressure generally increases with an increase in confining stress. In the conducted tests, the first injection 


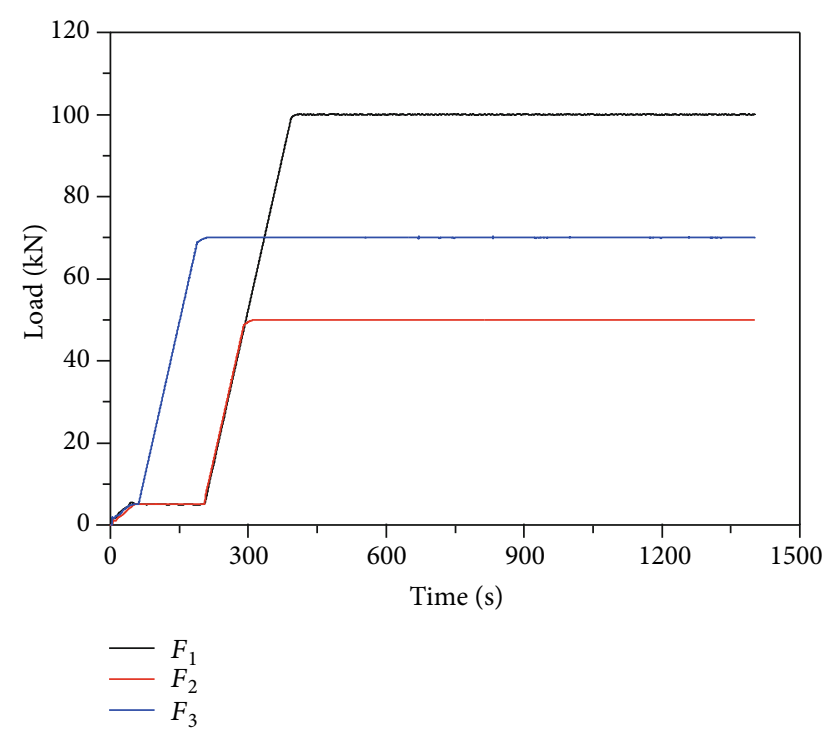

Figure 3: Typical loads applied to a cubic specimen.

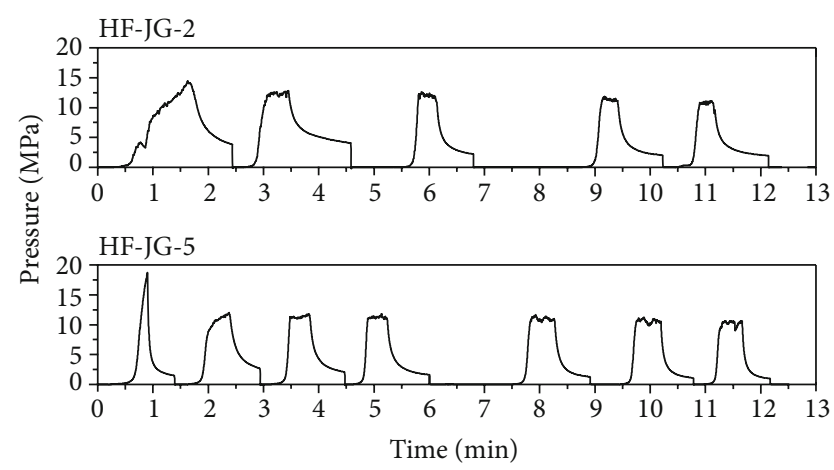

FIGURE 4: Typical experimental pressure-time curves corresponding to the HF tests of granite specimens.

cycle indicated the stable crack propagation, and the crack arrested finally. However, crack reopening occurred in the subsequent injection processes without further magnification of the crack length or rapidly reaching the boundary of the rock cube. Therefore, the crack lengths in the conducted tests are finite and deviated from the maximum principal stress orientation due to the confining stress effect.

\subsection{Results of the HF Tests for Sandstones with Preexisting} Cracks. Concerning the other considered specimens (red sandstones), the pressure-over-time curves are represented in Figure 6. The breakdown pressure, instantaneous shut-in pressure, and fracture reopening pressure in each test are clearly visible with acceptable reproducibility in each cycle. The typical characteristic parameters of these tests were interpreted, as listed in Table 3. In the case of applying the conventional stress measurement of HF and equation (2), the stresses corresponding to each cubic specimen were determined (see Table 3 ). The stresses obtained using equations (2) and (3) are close to the applied ones (theoretical values). The relative errors of $S_{\mathrm{hmin}}$ are less than $10 \%$, while the errors of $S_{\mathrm{Hmax}}$ are slightly higher, falling in the range of $5.88 \%-25.63 \%$. These results indicate that the conventional theory of HF based on the strength criterion can be used to approximately assess the stress values, particularly concerning the minimum horizontal principal stress.

As we noted above, the maximum horizontal principal stresses are inaccurately estimated using the conventional stress measurement theory due to the presence of preexisting fractures, and hydraulic fractures may initiate and propagate along these preexisting cracks. Therefore, the fracture mechanics methods must be used in HF analysis in this case. We employed the modified approaches for HF stress determination to analyze the results of these experiments. Here, fracture toughness was revised by incorporating the confining stress effect. The modified Rummel and Abou-Sayed methods were both utilized to calculate the maximum principal stress. The estimated stress results are represented in Table 4. The obtained results indicate that $S_{H \max }$ values obtained using the modified Rummel method are in the range of 10.1-10.96 MPa which are all lower than those determined through the modified Abou-Sayed method, thereby being closer to applied stresses (as shown in Table 4). The relative errors of $S_{H \max }$ obtained by the modified Rummel method are in the range of $2.0 \%-11.4 \%$, while they are approximately in the range of $16.0 \%-86.5 \%$ in the case of the modified Abou-Sayed method. This finding indicates that the Rummel method based on the superposition of stress intensity factors corresponding to each loading source is more accurate than the Abou-Sayed method.

The fracture morphology of the red sandstone specimens after the application of HF is represented in Figure 7. The maximum horizontal principal stresses loaded on these specimens were the same; however, the minimum horizontal principal stresses differed. Specimen HF-HS-4 has the lowest horizontal stress ratio $S_{\mathrm{hmin}} / S_{\mathrm{H} \max }$, namely, 0.5 , indicating a larger stress difference. We observed that the fracture of this specimen was nearly parallel to the maximum horizontal stress. Concerning specimen HF-HS-3, however, the stress ratio is the highest one which is close to 1 . Therefore, the crack path of HF-HS-3 deviated considerably from the direction of the maximum horizontal principal stress, as shown in Figure 7. The fracture morphology of other specimens was similar to that of HF-HS-3 and HF-HS-4 except the differences in the crack length and deviation angles. A higher stress difference leads to a lower deviation of crack orientation from maximum horizontal principal stress.

4.3. Discussion. Although equation (2) is still frequently used in field tests, as it does not require performing tensile strength measurements in cored rocks, a number of studies have argued about its reliability, especially in the case where no fracture reopening is clearly observed. The approach based on considering the tensile strength to calculate $S_{\mathrm{H} \max }$ is formulated in equation (1). It is deemed valid from the theoretical point of view, as long as a reliable tensile strength estimate can be obtained. The values of $S_{\mathrm{Hmax}}$ estimated based on the tensile strength combined with the conventional formula provided in equation (1) are represented in Figure 8 
TABLE 3: Summary of the experimental stress measurement data and the results based on equations (2) and (3).

\begin{tabular}{|c|c|c|c|c|c|c|c|c|c|c|c|}
\hline \multirow[t]{2}{*}{ No. } & \multirow[t]{2}{*}{ Rock type } & \multicolumn{4}{|c|}{$\mathrm{HF}$ parameters $(\mathrm{MPa})$} & \multicolumn{2}{|c|}{$\begin{array}{c}\text { Calculated stress } \\
(\mathrm{MPa})\end{array}$} & \multicolumn{2}{|c|}{$\begin{array}{l}\text { Applied stress } \\
(\mathrm{MPa})\end{array}$} & \multicolumn{2}{|c|}{$\begin{array}{c}\text { Relative error } \\
(\%)\end{array}$} \\
\hline & & $P_{\mathrm{b}}$ & $P_{\mathrm{r}}$ & $P_{\mathrm{s}}$ & $T$ & $S_{\text {Hmax }}$ & $S_{\mathrm{hmin}}$ & $S_{\text {Hmax }}$ & $S_{\mathrm{hmin}}$ & $e_{\mathrm{H} \max }$ & $e_{\mathrm{hmin}}$ \\
\hline HF-JG-2 & Granite & 14.42 & 8.40 & 5.16 & 6.02 & 7.08 & 5.16 & 9.83 & 4.86 & 27.98 & 6.24 \\
\hline HF-JG-5 & Granite & 18.73 & 8.77 & 7.63 & 9.96 & 14.12 & 7.63 & 14.53 & 7.33 & 2.82 & 4.11 \\
\hline HF-HS-1 & Sandstone & 13.01 & 7.75 & 6.16 & 5.31 & 10.73 & 6.16 & 9.76 & 6.11 & 9.89 & 0.79 \\
\hline HF-HS-3 & Sandstone & 14.56 & 9.79 & 7.41 & 4.77 & 12.44 & 7.41 & 9.95 & 6.22 & 25.63 & 0.80 \\
\hline HF-HS-4 & Sandstone & 10.61 & 7.69 & 5.34 & 2.92 & 8.33 & 5.34 & 9.90 & 7.47 & 15.35 & 8.11 \\
\hline HF-HS-5 & Sandstone & 9.70 & 7.83 & 5.72 & 1.87 & 9.33 & 5.72 & 9.84 & 4.94 & 5.88 & 4.28 \\
\hline
\end{tabular}

Notes: $P_{\mathrm{b}}$-breakdown pressure; $P_{\mathrm{r}}-$ fracture reopening pressure; $P_{\mathrm{s}}$-instantaneous shut-in pressure; $T$-tensile strength; $S_{\mathrm{hmin}}-$ minimum horizontal principal stress; $S_{\mathrm{H} \max }-$ maximum horizontal principal stress. Here, $e_{\mathrm{H} \max }=\left|S_{\mathrm{H} \max }{ }^{1}-S_{\mathrm{H} \max }\right| / S_{\mathrm{H} \max }$ and $e_{\mathrm{hmin}}=\left|S_{\mathrm{hmin}}{ }^{1}-S_{\mathrm{hmin}}\right| / S_{\mathrm{hmin}}$.

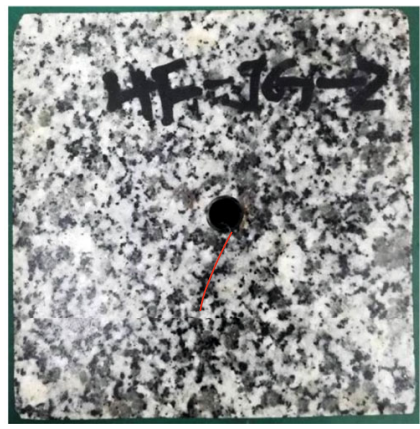

(a)

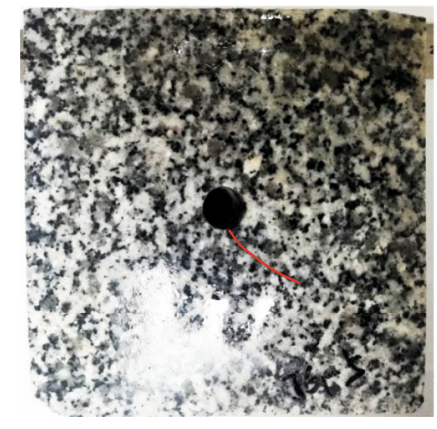

(b)

Figure 5: Fracture morphology after the HF tests of specimens: (a) HF-JG-2 and (b) HF-JG-5.
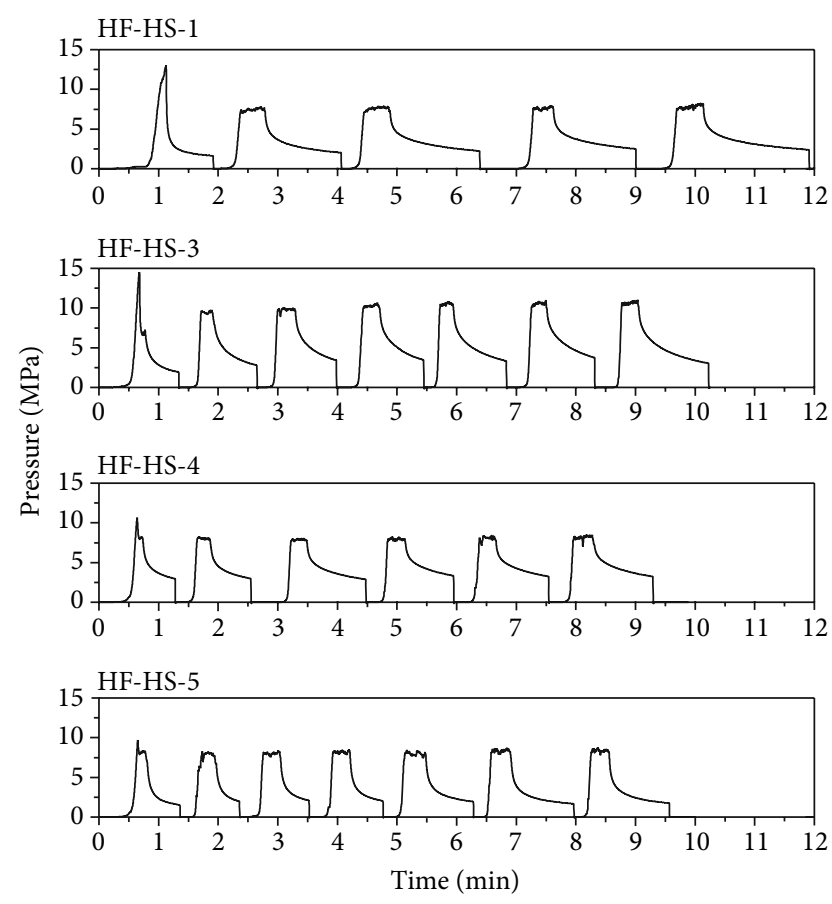

Figure 6: Pressure vs. time in the HF tests in the case of red sandstones. (purple triangles). The relative errors of $S_{\mathrm{Hmax}}$ are in the range of $8.9 \%-31.1 \%$. However, if preexisting cracks appear, these conventional equations based on the tensile strength are not applicable despite their relative conformity with applied stresses.

We compared the results obtained using four considered methods: two conventional and two fracture mechanics approaches (see Figure 8). We observed that the results obtained using the modified Rummel method (red columns) are closest to the applied stress values. The maximum relative error of the modified Rummel method is approximately $11.4 \%$, while the errors associated with the other three methods are all larger than $20 \%$. The errors of the estimated are induced not only by the interpretation of pressure with respect to a time curve but also by the measurement of the preexisting crack length and its propagation. The modified Rummel method based on fracture mechanics and the incorporation of the confining effect achieve the considerably more precise estimation of horizontal maximum principal stress.

The key parameter that may influence stress determination using the fracture mechanics method in laboratory and field tests is the fracture length. For granite samples, we located and identified hydraulic fractures using the ink dyeing method and micrometer. For sandstone samples, the crack propagation path could be clearly observed by the traces of injection fluid. Although these methods may seem rough, they could help us locate and identify the near- 
TABLE 4: Summary of the experimental stress measurement data and results based on the modified fracture mechanics methods.

\begin{tabular}{|c|c|c|c|c|c|c|c|c|c|}
\hline \multirow{2}{*}{ No. } & \multicolumn{4}{|c|}{ HF parameters $(\mathrm{MPa})$} & \multicolumn{3}{|c|}{ Calculated stress $(\mathrm{MPa})$} & \multicolumn{2}{|c|}{ Error (\%) } \\
\hline & $P_{\mathrm{b}}$ & $P_{\mathrm{r}}$ & $P_{\mathrm{s}}$ & $T$ & $S_{\mathrm{hmin}}$ & $S_{\mathrm{Hmax}}{ }^{\mathrm{R}}$ & $S_{\mathrm{H} \max }{ }^{\mathrm{A}}$ & $e_{\mathrm{H} \max }{ }^{\mathrm{R}}$ & $e_{\mathrm{hmin}}{ }^{\mathrm{A}}$ \\
\hline HF-HS-1 & 13.01 & 7.75 & 6.16 & 5.31 & 6.16 & 10.28 & 11.45 & 5.32 & 17.29 \\
\hline HF-HS-3 & 14.56 & 9.79 & 7.41 & 4.77 & 7.41 & 10.10 & 13.97 & $2.05 \%$ & $41.05 \%$ \\
\hline HF-HS-4 & 10.61 & 7.69 & 5.34 & 2.92 & 5.34 & 10.96 & 11.49 & $11.40 \%$ & $16.75 \%$ \\
\hline HF-HS-5 & 9.70 & 7.83 & 5.72 & 1.87 & 5.72 & 10.91 & 18.49 & $10.07 \%$ & $86.54 \%$ \\
\hline
\end{tabular}

Notes: $S_{\mathrm{H} \max }{ }^{\mathrm{R}}$ is the maximum horizontal principal stress determined using the modified Rummel method; $S_{\mathrm{H} \max }{ }^{\mathrm{A}}$ is the maximum horizontal principal stress obtained by the modified Abou-Sayed method; $e_{\mathrm{H} \max }{ }^{\mathrm{R}}=\left|S_{\mathrm{H} \max }{ }^{\mathrm{R}}-S_{\mathrm{H} \max }\right| S_{\mathrm{H} \max }$, and $e_{\mathrm{H} \max }{ }^{\mathrm{A}}=\left|S_{\mathrm{Hmax}}{ }^{\mathrm{A}}-S_{\mathrm{H} \max }\right| / S_{\mathrm{H} \max }$.

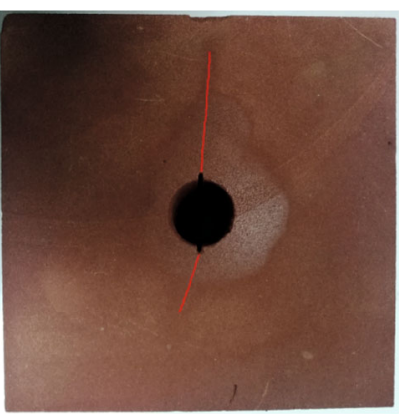

(a) HF-HS-1

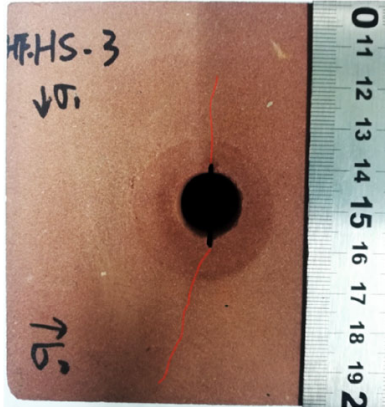

(b) HF-HS-3

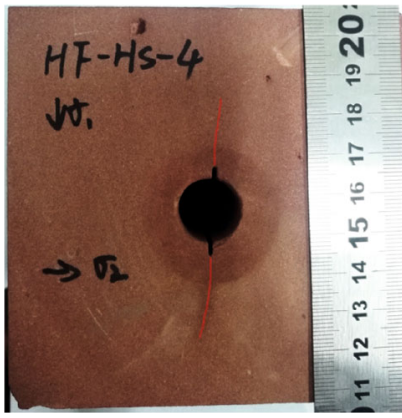

(c) HF-HS-4

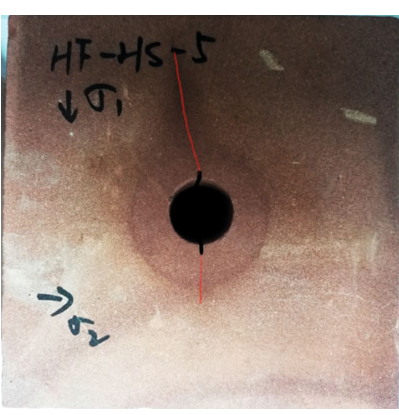

(d) HF-HS-5

FiguRE 7: Fracture morphology of the red sandstone specimens after hydraulic fracturing.

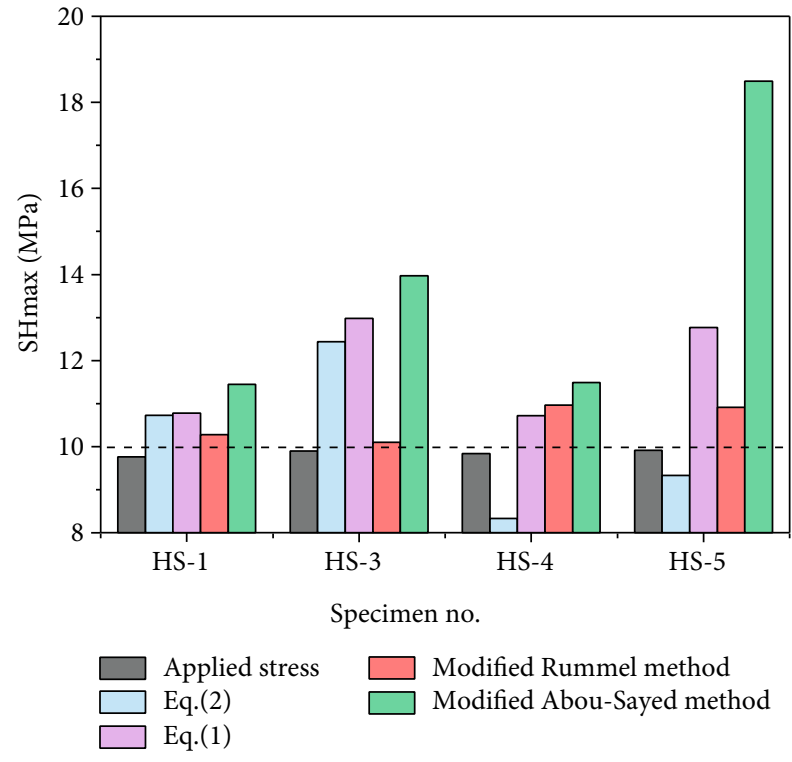

FIGURE 8: Estimated maximum horizontal principal stresses derived using the considered methods. Equations (1) and (2) correspond to the conventional methods for stress determination, while the modified Rummel and Abou-Sayed methods are the fracture mechanics approaches, expressed in equations (14) and (13), respectively.

surface fractures. In our future work, we plan to upgrade our true triaxial testing apparatus by incorporating an acoustic emission (AE) system to detect and identify induced frac- tures and microcracks during HF tests. Moreover, the highenergy computed tomography (CT) scan can be used to observe the fracture morphology of postfracturing rock samples.

\section{Conclusions}

The determination of in situ stress using the HF tests based on the conventional method has raised considerable controversies with regard to field tests, especially in the case of preexisting fractures. To address this issue, in the present paper, we proposed a modified fracture mechanics approach for stress determination considering the confinement effect in a deep hole. The relation between fracture toughness and confining pressure was incorporated by including dimension transformation. Then, we developed the modified Rummel and Abou-Sayed methods based on fracture mechanics.

Moreover, we conducted the true triaxial HF tests under different stress ratios for the granite and sandstone specimens to verify the applicability of the proposed approaches. We analyzed the typical pressure-time curves that indicated the steady fracture growth in these HF tests. Stresses were determined through the proposed fracture mechanics approaches and the methods based on conventional continuum mechanics. In the case without preexisting cracks, the conventional methods are deemed acceptable. In other cases with the preexisting fractures included, the modified fracture mechanics methods are confirmed to be reasonable and applicable. Analyzing the stress determination results obtained through different methods, we observed that the stresses determined using the modified Rummel method exhibit the lowest relative 
error and are consistent with applied stresses. The modification of the Rummel fracture mechanics method for stress determination allows obtaining the considerably precise estimation of maximum horizontal stress in $\mathrm{HF}$ stress measurement.

\section{Nomenclature}

a: $\quad$ Half crack length

$b$ : $\quad$ Dimensionless coefficient related to half crack length and borehole radius

F: $\quad$ Function of half crack length and borehole radius ratio $a / R$

$G$ : $\quad$ Function of half crack length and borehole radius ratio $a / R$

$K_{\mathrm{I}}$ : $\quad$ Stress intensity factor of mode I fracture

$K_{\text {Ic }}: \quad$ Fracture toughness

$K_{\mathrm{Ic}}^{0}: \quad$ Fracture toughness at ambient pressure

$K_{\mathrm{Ic}}^{\prime}$ : Fracture toughness under confining pressure

$p: \quad$ Fluid pressure acting on the wall of a hole

$p_{\mathrm{a}}$ : $\quad$ Fluid pressure distribution along the crack

$P_{0}$ : $\quad$ Pore pressure

$P_{\mathrm{b}}: \quad$ Breakdown pressure

$P_{\text {conf }}$ : Confining pressure

$P_{\mathrm{r}}: \quad$ Fracture reopening pressure

$P_{s}: \quad$ Instantaneous shut-in pressure

$R: \quad$ Radius of a borehole

$S_{\text {Hmax }}$ : Maximum horizontal principal stress

$S_{\text {hmin }}$ : Minimum horizontal principal stress

$T_{0}$ : Tensile strength of surrounding rock

AE: Acoustic emission

CT: Computed tomography

DFIT: Diagnostic fracture injection test

HF: Hydraulic fracturing

HTPF: Hydraulic tests on preexisting fractures

ISRM: International Society for Rock Mechanics and Rock Engineering.

\section{Data Availability}

The original test data used to support the findings of this study are available from the corresponding author upon request.

\section{Conflicts of Interest}

The authors declare that they have no conflicts of interest.

\section{Acknowledgments}

The authors would like to thank Enago (https://www.enago .cn) for the English language review. This work was supported by the research grant (No. ZDJ2020-07) from National Institute of Natural Hazards, MEMC (former Institute of Crustal Dynamics, China Earthquake Administration), Open Fund of Key Laboratory of Shale Gas Exploration, Ministry of Natural Resources (KLSGE-MLR201904), and National Natural Science Foundation of China (41704096).

\section{References}

[1] R. C. Alt and M. D. Zoback, "In SituStress and active faulting in Oklahoma," Bulletin of the Seismological Society of America, vol. 107, no. 1, pp. 216-228, 2017.

[2] F. H. Cornet, "The engineering of safe hydraulic stimulations for EGS development in hot crystalline rock masses," Geomechanics for Energy and the Environment, no. article 100151, 2019.

[3] H. Dev, "Evaluation of in-situ stresses in rock mass: challenges and applications in hydropower development," Journal of Rock Mechanics and Tunnelling Technology, vol. 25, no. 2, pp. 103$112,2019$.

[4] X. Guo, K. Wu, C. An, J. Tang, and J. Killough, "Numerical investigation of effects of subsequent parent-well injection on interwell fracturing interference using reservoirgeomechanics-fracturing modeling," SPE Journal, vol. 24, no. 4, pp. 1884-1902, 2019.

[5] X. Guo, K. Wu, and J. Killough, "Investigation of productioninduced stress changes for infill-well stimulation in Eagle Ford Shale," SPE Journal, vol. 23, no. 4, pp. 1372-1388, 2018.

[6] Y. Jo, C. Chang, S. Ji, and K. Park, "In situ stress states at KURT, an underground research laboratory in South Korea for the study of high-level radioactive waste disposal," Engineering Geology, vol. 259, p. 105198, 2019.

[7] Y. Li, M. Long, J. Tang, M. Chen, and X. Fu, "A hydraulic fracture height mathematical model considering the influence of plastic region at fracture tip," Petroleum Exploration and Development, vol. 47, no. 1, pp. 184-195, 2020.

[8] P. Segall and S. D. Fitzgerald, "A note on induced stress changes in hydrocarbon and geothermal reservoirs," Tectonophysics, vol. 289, no. 1-3, pp. 117-128, 1998.

[9] C. Wang, C. Song, Q. Guo, J. Mao, and Y. Zhang, "New insights into stress changes before and after the Wenchuan earthquake using hydraulic fracturing measurements," Engineering Geology, vol. 194, pp. 98-113, 2015.

[10] B. Amadei and O. Stephansson, Rock stress and its measurement, Chapman \& Hall, London, 1997.

[11] C. Lin, D. S. Zou, and H. Sun, "Exploration of measurement methods of 3D in-situ stresses in rock masses," International Journal of Georesources and Environment-IJGE (formerly International Journal of Geohazards and Environment), vol. 5, no. 1, pp. 1-13, 2019.

[12] B. C. Haimson and F. H. Cornet, "ISRM suggested methods for rock stress estimation-part 3: hydraulic fracturing (HF) and/or hydraulic testing of pre-existing fractures (HTPF)," International Journal of Rock Mechanics and Mining Sciences, vol. 40, no. 7-8, pp. 1011-1020, 2003.

[13] M. D. Zoback, Reservoir geomechanics, Cambridge University Press, Cambridge, 2010.

[14] T. Ito, K. Evans, K. Kawai, and K. Hayashi, "Hydraulic fracture reopening pressure and the estimation of maximum horizontal stress," International Journal of Rock Mechanics and Mining Sciences, vol. 36, no. 6, pp. 811-826, 1999.

[15] J. Rutqvist, C. F. Tsang, and O. Stephansson, "Uncertainty in the maximum principal stress estimated from hydraulic fracturing measurements due to the presence of the induced fracture," International Journal of Rock Mechanics and Mining Sciences, vol. 37, no. 1-2, pp. 107-120, 2000.

[16] X. Jin, S. N. Shah, J.-C. Roegiers, and B. Hou, "Breakdown pressure determination-a fracture mechanics approach," in 
SPE Annual Technical Conference and Exhibition, New Orleans, Louisiana, USA, 2013.

[17] S. Hickman and M. Zoback, "Stress orientations and magnitudes in the SAFOD pilot hole," Geophysical Research Letters, vol. 31, no. L15S12, pp. 1-4, 2004.

[18] A. Bunger, A. Lakirouhani, and E. Detournay, "Modelling the effect of injection system compressibility and viscous fluid flow on hydraulic fracture breakdown pressure," in Rock Stress and Earthquakes, pp. 59-67, 2010.

[19] J. Tang, K. Wu, L. Zuo, L. Xiao, S. Sun, and C. Ehlig-Economides, "Investigation of rupture and slip mechanisms of hydraulic fractures in multiple-layered formations," SPE Journal, vol. 24, no. 5, pp. 2292-2307, 2019.

[20] F. H. Cornet and B. Valette, "In situ stress determination from hydraulic injection test data," Journal of Geophysical Research, vol. 89, no. B13, pp. 11527-11537, 1984.

[21] J. J. Hildebrand and Y. Liang, "DFIT analysis and simulation in shale formations: a Utica case study," in SPE Annual Technical Conference and Exhibition, pp. 1-20, Calgary, Alberta, Canada, 2019.

[22] H. Wang and M. M. Sharma, "Determine in-situ stress and characterize complex fractures in naturally fractured reservoirs from diagnostic fracture injection tests," Rock Mechanics and Rock Engineering, vol. 52, no. 12, pp. 5025-5045, 2019.

[23] A. Abou-Sayed, C. Brechtel, and R. Clifton, "In situ stress determination by hydrofracturing: a fracture mechanics approach," Journal of Geophysical Research: Solid Earth, vol. 83, no. B6, pp. 2851-2862, 1978.

[24] E. Detournay and R. Carbonell, "Fracture-mechanics analysis of the breakdown process in minifracture or leakoff test," SPE Production \& Facilities, vol. 12, no. 3, pp. 195-199, 1997.

[25] F. Rummel, "Fracture mechanics approach to hydraulic fracturing stress measurements," in Fracture Mechanics of Rock, B. K. Atkinson, Ed., pp. 217-240, Academic Press, 1987.

[26] F. Stoeckhert, S. Brenne, M. Molenda, and M. Alber, "Fracture mechanical evaluation of hydraulic fracturing laboratory experiments," in Rock Engineering and Rock Mechanics: Structures in and on Rock Masses, pp. 1335-1340, International Society for Rock Mechanics and Rock Engineering, Vigo, Spain, 2014.

[27] R. J. Fowell, J. A. Hudson, C. Xu, and J. F. Chen, "Suggested method for determining mode I fracture toughness using cracked chevron notched Brazilian disc (ccnbd) specimens," International Journal of Rock Mechanics and Mining Sciences \& Geomechanics Abstracts, vol. 32, no. 1, pp. 57-64, 1995.

[28] M. D. Kuruppu, Y. Obara, M. R. Ayatollahi, K. P. Chong, and T. Funatsu, "ISRM-suggested method for determining the mode I static fracture toughness using semi-circular bend specimen," Rock Mechanics and Rock Engineering, vol. 47, no. 1, pp. 267-274, 2014.

[29] T. Funatsu, M. Seto, H. Shimada, K. Matsui, and M. Kuruppu, "Combined effects of increasing temperature and confining pressure on the fracture toughness of clay bearing rocks," International Journal of Rock Mechanics and Mining Sciences, vol. 41, no. 6, pp. 927-938, 2004.

[30] S. Thallak, J. Holder, and K. E. Gray, "The pressure dependence of apparent hydrofracture toughness," International Journal of Rock Mechanics and Mining Sciences \& Geomechanics Abstracts, vol. 30, no. 7, pp. 831-835, 1993.

[31] B. Vásárhelyi, "Influence of pressure on the crack propagation under mode I loading in anisotropic gneiss," Rock Mechanics and Rock Engineering, vol. 30, no. 1, pp. 59-64, 1997.
[32] N. A. Al-Shayea, K. Khan, and S. N. Abduljauwad, "Effects of confining pressure and temperature on mixed-mode (I-II) fracture toughness of a limestone rock," International Journal of Rock Mechanics and Mining Sciences, vol. 37, no. 4, pp. 629643, 2000.

[33] M. Kataoka, E. Mahdavi, T. Funatsu et al., "Estimation of mode I fracture toughness of rock by semi-circular bend test under confining pressure condition," Procedia Engineering, vol. 191, pp. 886-893, 2017.

[34] R. A. Schmidt and C. W. Huddle, "Effect of confining pressure on fracture toughness of Indiana limestone," International Journal of Rock Mechanics and Mining Sciences \& Geomechanics Abstracts, vol. 14, no. 5-6, pp. 289-293, 1977.

[35] B. Haimson and C. Fairhurst, "Initiation and extension of hydraulic fractures in rocks," Society of Petroleum Engineers Journal, vol. 7, no. 3, pp. 310-318, 1967.

[36] M. K. Hubbert and D. G. W. Willis, "Mechanics of hydraulic fracturing," Petroleum Transactions of the AIME, vol. 210, no. 1, pp. 153-168, 1957.

[37] A. Abdollahipour, M. Fatehi Marji, A. Yarahmadi Bafghi, and J. Gholamnejad, "DEM simulation of confining pressure effects on crack opening displacement in hydraulic fracturing," International Journal of Mining Science and Technology, vol. 26, no. 4, pp. 557-561, 2016.

[38] F. Rummel and J. Hansen, "Interpretation of hydrofrac pressure recordings using a simple fracture mechanics simulation model," International Journal of Rock Mechanics and Mining Sciences \& Geomechanics Abstracts, vol. 26, no. 6, pp. 483488, 1989.

[39] P. C. Paris and G. C. Sih, Stress Analysis of Cracks, Fracture Toughness Testing and Its Applications, ASTM International, West Conshohocken, PA, 1965.

[40] J. Shlyapobersky, "Energy analysis of hydraulic fracturing," in The 26th US Symposium on Rock Mechanics (USRMS), pp. 539-546, Rapid City, South Dakota, 1985.

[41] W. Müller, "Brittle crack growth in rocks," Pure and Applied Geophysics, vol. 124, no. 4-5, pp. 693-709, 1986.

[42] R. B. Winter, Bruchmechanische Gesteinsuntersuchungen mit dem Bezug zu hydraulischen Frac-Versuchen in Tiefbohrungen, Institut für Geophysik, Ruhr-Universität Bochum, 1983.

[43] F. Stoeckhert, S. Brenne, M. Molenda, and M. Alber, "Mode I fracture toughness of rock under confining pressure," in ISRM International Symposium - EUROCK 2016, R. Ulusay, Ed., pp. 313-318, International Society for Rock Mechanics and Rock Engineering, Ürgüp, Turkey, 2016.

[44] A. S. Abou-Sayed, “An experimental technique for measuring the fracture toughness of rocks under downhole stress condition," VDI-Berichte, vol. 313, pp. 819-824, 1978.

[45] M. D. Kuruppu and M. Seto, "Determination of fracture toughness of rock under in-situ conditions using semicircular specimen," Optica Acta, vol. 107, no. 4, pp. 733-741, 2013.

[46] F. Stoeckhert, Fracture Mechanics Applied to Hydraulic Fracturing in Laboratory Experiments, Ruhr University Bochum, Bochum, 2015.

[47] G. Gao, C. Wang, P. Wang, and R. Yang, "The relationship between fracture toughness and confining pressure," in ISRM 2019. Rock Mechanics for Natural Resources and Infrastructure Development, S. A. B. D. Fontoura, R. J. Rocca, and J. P. Mendoza, Eds., pp. 1030-1036, CRC Press, Foz de Iguassu, Brazil, 2019. 
[48] S. Yang, L. Huang, F. Xie, X. Cui, and R. Yao, "Quantitative analysis of the shallow crustal tectonic stress field in China mainland based on in situ stress data," Journal of Asian Earth Sciences, vol. 85, pp. 154-162, 2014.

[49] C. Wang, B. Xing, Y. Jiang, and L. Zhu, "Development and application of interactive software for determination of hydraulic fracturing stress measurement parameters," Journal of Engineering Geology, vol. 24, no. s1, pp. 1347-1354, 2016. 